\title{
Estimating confidence limits on a standardised mortality ratio when the expected number is not error free
}

\author{
Paul Silcocks
}

\begin{abstract}
Objective - The aim was to demonstrate how the beta distribution may be used to find confidence limits on a standardised mortality ratio (SMR) when the expected number of events is subject to random variation and to compare these limits with those obtained with the standard exact approach used for SMRs and with a Fieller-based confidence interval.

Design - The relationship of the binomial and the beta distributions is explained. For cohort studies in which deaths are counted in exposed and unexposed groups exact confidence limits on the relative risk are found conditional on the total number of observed deaths. A similar method for the SMR is justified by analogy between the SMR and the relative risk found from such cohort studies, and the fact that the relevant (beta) distribution does not require integer parameters.
\end{abstract}

Source of data - Illustrative examples of hypothetical data were used, together with a MINITAB macro (see appendix) to perform the calculations.

Main results - Exact confidence intervals that include error in the expected number are much wider than those found with the standard exact method. Fieller intervals are comparable with the new exact method provided the observed and expected numbers (taken to be means of Poisson variates) are large enough to approximate normality. As the expected number is increased, the standard method gives results closer to the new method, but may still lead to different conclusions even with as many as 100 expected.

Conclusions - If there is reason to suppose the expected number of deaths in an SMR is subject to sampling error (because of imprecisely estimated rates in the standard population) then exact confidence limits should be found by the methods described here, or approximate Fieller-based limits provided enough events are observed and expected to approximate normality.

( Epidemiol Community Health 1994;48:313-317)

In general, when confidence limits are found for a standardised mortality ratio (SMR), the observed value is treated as a Poisson variate, while the expected number is regarded as error-free. ${ }^{1}$ Often confidence limits on the observed number are found by treating it as approximately "normal", but a better method is to use the relation between the Poisson and $\chi^{2}$ distributions to get exact limits. ${ }^{2}$

The present paper was motivated by a medical student's project, which compared observed and expected numbers of hospital admissions for Asian patients on a general practitioner's list. The expected numbers for each age/sex band were found by applying the corresponding admission rates for whites to the Asian population at risk. Because the study was based on data from a single practice, it is reasonable to assume that the rates from which the expected number of admissions were found were themselves imprecisely estimated. Similar considerations would apply if deaths rather than admissions had been of interest. Under such circumstances the standard approach is invalid because the expected number of deaths will be subject to random variation. The problem is how to take this extra source of variability into account when assessing the statistical significance of an SMR.

One approach might be to find the exact sampling distribution but this is mathematically intractable. Another, approximate, method that would apply only if both observed and expected numbers were large enough to be treated as if normally distributed, would be to use Fieller's theorem for obtaining confidence limits on the ratio of two normal variables. ${ }^{3}$ Note that the ratio itself has a Cauchy distribution so there is no point in attempting to take standard errors as the variance does not exist. The Fieller-based approach is as follows using Liddell's ${ }^{2}$ notation where $\mathrm{D}=$ observed number of deaths and $E=$ expected number:

$$
\mathrm{SMR}=\mathrm{D} / \mathrm{E}=\mathrm{R} \text { (say) }
$$

Then if $D$ and $E$ are normal, so will (D-E*R) be normal and

$$
\begin{aligned}
\frac{\left(D-E^{*} R\right)^{2}}{\operatorname{Var}\left(D-E^{*} R\right)} \sim & \text { approximately as } \chi^{2} \text { on } \\
& 1 \text { degree of freedom }
\end{aligned}
$$

$95 \%$ Confidence intervals for $\mathrm{R}$ are solutions to the quadratic equation in $\mathrm{R}$;

$$
\begin{gathered}
\mathrm{R}^{2 *} \mathrm{E}^{*}\left(\mathrm{E}-\chi^{2}\right)-\mathrm{R}^{*}\left(2 * \mathrm{D} * \mathrm{E}-2 * \mathrm{D}^{*} \mathrm{q}^{*} \chi^{2}\right)+ \\
\mathrm{D} *\left(\mathrm{D}-\chi^{2}\right)=0
\end{gathered}
$$

Where we use the fact that $\operatorname{var}(\mathbf{x})=\mathbf{x}$ for a Poisson variate and $\chi^{2}$ is the appropriate critical value for $\chi^{2}: 3 \cdot 8416$ in this instance. Here $q$ 
is the mean proportion of the standard population contributed by the index population, averaged across age bands and weighted by the number of observed events in each age band. This would apply, for example, when the mortality rate for an electoral ward is standardised on the health district of which it forms a part. As indicated above, however, this approach will not apply if we cannot assume normality for $\mathrm{D}$ and $\mathrm{E}$ (for example when we have only small numbers of events) so some other method is needed. Equation (3) is derived in appendix 1 .

\section{Method}

In the context of a cohort study or randomised controlled trial where we want confidence limits on a relative risk derived from an exposed and an unexposed group, one method is to condition on the total number of observed events and find confidence limits on the proportion $p$ of events that occur in the exposed group. ${ }^{4}$ We have the following relations:

$$
\mathrm{p}=\mathrm{r} 1 /(\mathrm{r} 1+\mathrm{r} 2)
$$

$r 1, r 2$ are observed events in exposed and unexposed groups.

$$
\begin{aligned}
& \text { Relative risk }= \\
& \quad(\mathrm{r} 1 / \mathrm{r} 2)^{*}(\mathrm{n} 2 / \mathrm{n} 1)=[\mathrm{p} /(1-\mathrm{p})]^{*}(\mathrm{n} 2 / \mathrm{n} 1)
\end{aligned}
$$

$\mathrm{n} 1, \mathrm{n} 2$ are person-years at risk or population sizes for exposed and unexposed.

Confidence intervals on the relative risk are obtained by finding lower and upper confidence limits for $p$ and substituting these in (5). Since $\mathrm{p}$ is a binomial proportion, exact confidence limits can be found by exploiting the well-known relation between the beta distribution and the binomial. ${ }^{5}$ Specifically the integral:

$$
\begin{aligned}
& G(k)=\int_{z=p}^{z=1} \frac{n !}{(k-1) !(n-k) !} \\
& \mathrm{z}^{(\mathrm{k}-1) *}(1-\mathrm{z})^{(\mathrm{n}-\mathrm{k})} \cdot \mathrm{dz}=\operatorname{Pr}\left(\mathrm{z}^{\bullet} \mathrm{p}\right)
\end{aligned}
$$

is equal to the binomial expansion:

$$
\sum_{j=0}^{j=k-1}\left(\begin{array}{c}
n \\
j
\end{array}\right) p^{\left.j *(1-p)^{n-j}\right)}
$$

giving $\operatorname{Pr}(r<k)$, where $r$ is a count of events.

Now $G(k)$ is $1-B e(p, k, n-k+1)$ where $B e$ is the incomplete beta function (that is, the beta cumulative distribution function for $\mathrm{z}=\mathrm{p}$ ), and so we have:

$$
\begin{gathered}
\operatorname{Pr}(\mathrm{z} \leqslant \mathrm{p})=1-\operatorname{Pr}(\mathrm{z}>\mathrm{p})=1-\operatorname{Pr}(\mathrm{r}<\mathrm{k})= \\
\operatorname{Be}(\mathrm{p}, \mathrm{k}, \mathrm{n}-\mathrm{k}+1)
\end{gathered}
$$

and since $\operatorname{Pr}(r>k)=1-\operatorname{Pr}(r<k+1)$,

$\operatorname{Pr}(r>k)=1-G(k+1)=B e(p, k+1, n-k)$

So, the lower $95 \%$ confidence limit for $\mathrm{p}$ is the value of $p$ such that $B e(p, k, n-k+1)=0.025$ while the upper limit satisfies $\operatorname{Be}(\mathrm{p}, \mathrm{k}+1, \mathrm{n}-\mathrm{k})=0.975$. In the past these values have been obtained by further exploiting the relation between $\mathrm{Be}$ and $\mathrm{F}$ distributions, but this is no longer needed as packages like MINITAN ${ }^{6}$ give the $B e$ cumulative distribution function and inverse cumulative distribution function directly.

Now an SMR can be thought of as the relative risk obtained by comparison of an "exposed" group (the index population) with a synthetic "unexposed" group derived from the standard population. If the standard population is distinct from the index, or if the index population is only a small fraction of the standard so that the covariance of $D$ and $E$ is negligible, then the position is just as described above, except that the total number of events need not be an integer. The Be function parameters do not need to be integers, however, and so we can find confidence limits on $p$ exactly as if we had followed up two real groups. This argument gives confidence limits that preserve the integer character of the observed number of events.

A MINITAB macro is listed in appendix 2 that finds these confidence limits:

(a) Assuming no error in the expected number of events;

(b) By the method described above (which assumes no covariance between $\mathrm{D}$ and $\mathrm{E}$ );

(c) Using Fieller's theorem (different amounts of overlap between index and standard populations can be allowed for by varying the quantity q).

For those unhappy with the use of a noninteger value for the denominator of a proportion, virtually the same results will be found with the following approach. Take the expected number of events to be an estimate of the (integer) number that would have been found with a real comparison group. Suppose 2.8 events are expected - in reality we would have obtained 2 or 3 . We can find an SMR (and confidence limits) separately for 2 and then for 3 events, and obtain the actual SMR as the appropriately weighted harmonic mean of the separate SMRs:

$$
\frac{\mathrm{D}}{0 \cdot 2^{*} \mathrm{E} 1+0 \cdot 8^{*} \mathrm{E} 2}=\frac{1}{(0 \cdot 2 / \mathrm{SMR} 1)+(0 \cdot 8 / \mathrm{SMR} 2)}
$$

with SMR1 and SMR2 being the SMRs found using the integer expected values. Confidence limits are obtained by substituting the corresponding limits on SMR1 and SMR2.

\section{Results}

For seven observed events with $2 \cdot 8$ expected: the SMR is 2.5 with exact $95 \%$ confidence limits of 1.005 to 5.151 , assuming no error in the expected value, and limits of 0.5548 to 16.0921 assuming error, found using the $\mathrm{Be}$ distribution. 
Table 1 Comparison of exact, Fieller, and standard confidence limits

\begin{tabular}{llll}
\hline & \multicolumn{2}{l}{ Observed/expected } & \\
\cline { 2 - 4 } Method & $7 / 5$ & $14 / 10$ & $140 / 100$ \\
\hline "Exact" limits & 0.382 to 5.595 & 0.578 to 3.523 & 1.075 to 1.828 \\
Fieller limits & 0.325 to 11.76 & 0.583 to 3.964 & 1.085 to 1.827 \\
Standard limits & 0.563 to 2.885 & 0.765 to 2.349 & 1.178 to 1.652 \\
\hline
\end{tabular}

Using interpolation: $2 \cdot 8=0 \cdot 2 * 2+0 \cdot 8 * 3$

\begin{tabular}{llll} 
& $\begin{array}{l}\text { Expected } \\
\text { no }\end{array}$ & $\begin{array}{l}\text { SMR } \\
2\end{array}$ & $\begin{array}{l}(95 \% \text { confidence } \\
\text { limits })\end{array}$ \\
Weighted & 3 & 2.5 & 0.6664 to 34.5329 \\
mean $=$ & 2.8 & 2.5 & 0.5327 to 13.9837 \\
\cline { 2 - 3 } & 2.5549 to 15.8728
\end{tabular}

If we assume that a Poisson distribution with a mean of 10 or more will be satisfactorily "normal" (based on the relation $\left.\left\{\mathbf{x}-3^{*} \sqrt{ }(\mathbf{x})\right\}>=0\right)$ then we can compare the confidence limits found using Fieller's theorem, for an SMR of 1.4, say, with different observed and expected values (table 1 ).

When the index population (for which the SMR is to be calculated) forms part of the standard, then the observed and expected numbers of deaths must be correlated. To assess the effect of this, we require the quantity $\mathrm{q}$, which is a weighted average of the proportions in each age band of the standard population, contributed by the index population. Calculation of $\mathrm{q}$ using routine data, and its effect are illustrated in table 2. The effect of different values of $\mathrm{q}$ is illustrated in table 3 , using Fieller confidence limits. When $\mathrm{q}=0$ then observed and expected numbers are independent, but when $\mathrm{q}>0$ the correlation between them narrows the width of the confidence interval.

Table 2 Example: myeloid leukaemia (males) in Derbyshire and Trent Regional Health Authority ( $R H A$ )

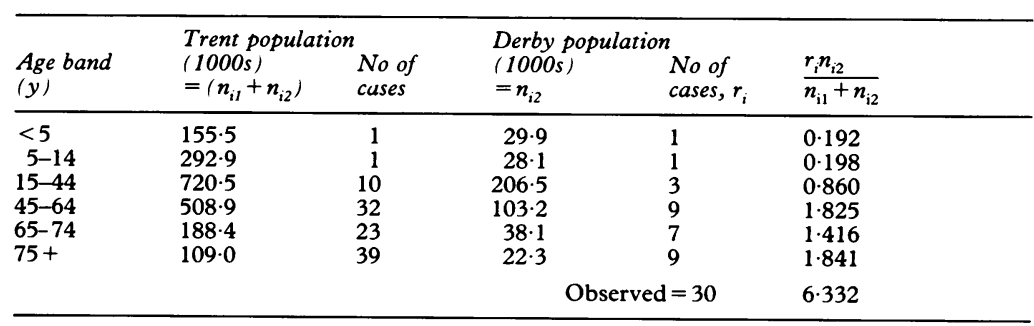

Mean fraction of Trent RHA male population contributed by Derbyshire $=q=6 \cdot 332 / 30=0 \cdot 211$. Expected no (based on whole of Trent region) $=22 \cdot 376$.

SMR $=30 / 22 \cdot 376=1 \cdot 341$ "Usual" 95\% confidence limits: 0.905 to 1.914

Fieller-based confidence limits: 0.824 to $2 \cdot 295$

Expected no (based on Trent having excluded Derbyshire) $=20.435$.

SMR $=30 / 20 \cdot 435=1.468$ Exact $95 \%$ confidence limits: 0.809 to $2 \cdot 714$

Fieller-based confidence limits $(\mathrm{q}=0): 0.831$ to $2 \cdot 785$.

Sources: Mortality Statistics Area 1989, OPCS Series DH5 no 16 and Key Population and Vital

Statistics - Local and Health Authority Areas 1989. Series VS no 16 and PP1 no 12

Table 3 Effect of covariance between observed ( $n=15)$ and expected $(n=12)$ deaths (Fieller-based limits)

\begin{tabular}{|c|c|c|c|c|c|}
\hline & \multicolumn{4}{|c|}{$\begin{array}{l}\text { Fraction of the standard population } \\
\text { represented by the index population }\end{array}$} & \multirow[b]{2}{*}{ Exact limits } \\
\hline & $0.2^{4}$ & $0 \cdot 1$ & 0.05 & 0 & \\
\hline $\begin{array}{l}\text { Lower } 95 \% \text { limit } \\
\text { Upper } 95 \% \text { limit }\end{array}$ & $\begin{array}{l}0.559 \\
3.057\end{array}$ & $\begin{array}{l}0.553 \\
3.094\end{array}$ & $\begin{array}{l}0 \cdot 549 \\
3 \cdot 113\end{array}$ & $\begin{array}{l}0 \cdot 546 \\
3 \cdot 131\end{array}$ & $\begin{array}{l}0.546 \\
2 \cdot 925\end{array}$ \\
\hline
\end{tabular}

That the Fieller approach breaks down completely with small numbers is seen from the Fieller confidence limits obtained for 7 observed and $2 \cdot 8$ expected, which are 0.542 to $(-) 13.983$.

\section{Discussion}

It is clear that it is very easy to obtain false impressions both of statistical significance and of precision using the standard approach.

If we assume that a $10 \%$ coefficient of variation is the maximum tolerable for an estimate of some "baseline" value (even tighter coefficients of variation are common in laboratory medicine) then we might assume the expected number to include random variation if the average coefficient of variation of the rates from which the expected numbers will be estimated exceeds $10 \%$.

Alternatively, we might assume that the denominator of any SMR will be subject to random variation. The justification for this view is consistency: when comparing the mortality in a health district with that in the parent region, the expected number of deaths derived from regional rates is assumed to be error-free; yet if regional observed deaths (which go to form the regional rates) are compared with those expected from national rates, somehow they are now assumed to be subject to error. Hence when the denominator is less than about 100 , so that the expected number has coefficient of variation more than $10 \%$ "exact" limits should be used. Even with this cut off our conclusions may be less well justified than we think. For example, with 125 observed events and 100 expected, the confidence limits assuming no error in the denominator are: 1.04 to 1.49 , but these are 0.95 to 1.64 if we allow for error.

Fieller-based limits are similar to the exact values once approximate normality holds, but break down with small numbers of events. On the other hand these limits can easily accommodate covariance between observed and expected values, unlike the exact method.

Random variation (taken to be Poisson) in the numbers at risk in the index population can reasonably be ignored. In England and Wales the all-causes mortality rate is of the order of $280 / 100000 / y$ so to get a "reasonable" number of observed deaths such as 5 , one would need of the order of 2000 person-years, which for a 20 year period gives $n=100$ with cofficient of variation at $10 \%$. For particular causes of death with lower mortality rates, of course, the numbers at risk would need to be greater still, with correspondingly less sampling error.

An additional potentially rather interesting 
consequence of beta-distribution derived confidence limits is that as none of the parameters need to be integer, we could compare disease rates in two cohorts where "definite" cases were scored as a " 1 " and less well established cases were given a value between 0 and 1 . The advantage would be that we would avoid the problems of over- and under-diagnosis respectively caused by including or excluding "suspicious" cases. Alternatively, non-integer values could be the result of weighting each event by some measure of severity provided this ranges from 0 to 1 . The relative risk would be found using equation (5), with confidence limits for $(\mathrm{r} 1 / \mathrm{r} 2)$ being obtained from the macro given here, on substituting $\mathrm{rl}$ for observed deaths and $\mathrm{r} 2$ for expected deaths and putting $\mathrm{q}=0$.

Exact statistical methods are now becoming more widely available, as in the StatXact package ${ }^{7}$ and can both reject and confirm conclusions based on classical methods. For the SMR, however, it is not necessary to have expensive, specialised software, and the wider limits given by exact methods - especially when error in the expected number is allowed for - may help prevent over hasty, unjustified decision making both in epidemiology and in public health.

1 Kahn HA, Sempos CT. Statistical methods in epidemiology. New York, Oxford University Press, 1989.

2 Liddell FDK. Simple exact analysis of the standardized mortality ratio. $\mathcal{F}$ Epidemiol Community Health 1984;38:85-

Fieller EC. Some problems in interval estimation. fournal of

the Royal Statistical Society B 1954;16:175-183.

Poisson variables. Am ₹ Epidemiol 1974;100:165-167.

5 Dudewicz EJ, Mishra SN. Modern mathematical statistics. Chichester: John Wiley \& Son, 1988;54.

6 MINIT AB reference manual. Release 7. Pennsylvania: Minitab Inc, 1989.

7 Mehta CR, Patel NR. StatXact user manual. Version 2. Cambridge MA: Cytel Software, 1991.

\section{Appendix 1}

DERIVATION OF EQUATION 3

Consider two subpopulations. One is the index population, while the standard population is the sum of the subpopulations.

For simplicity consider only age-standardisation.

Let $\mathrm{D}=$ observed deaths in index population; Let $\mathrm{E}=$ expected deaths in index population; Let the estimated death rate in the ith age band in subpopulation $\mathrm{j}$ be $r_{\mathrm{ij}} / \mathrm{n}_{\mathrm{ij}}$;

$$
\text { Then } D=\sum_{i} r_{i 1}
$$

$\&$

$$
\begin{aligned}
E & =\sum_{i} \frac{n_{i j}\left\{r_{i 1}+r_{i 2}\right\}}{\left\{n_{i 1}+n_{i 2}\right\}} \\
& =\sum_{i} p_{i}^{*}\left(r_{i 1}+r_{i 2}\right)
\end{aligned}
$$

where $p_{i}$ is the proportion of the ith age band in the combined (standard) population.
Now

$$
\begin{gathered}
\operatorname{covar}(D, E)=\operatorname{covar}\left\{\sum_{i} r_{i 1}, \sum_{i} p_{i}^{*}\left(r_{i 1}+r_{i 2}\right)\right\} \\
=\operatorname{covar}\left\{\sum_{i} r_{i 1}{ }^{*} p_{i}^{*}\left(r_{i 1}+r_{i 2}\right)+\sum_{i \neq} \sum_{j} r_{i 1}{ }^{*} p_{i}^{*}\left(r_{j 1}+r_{j 2}\right)\right. \\
=\sum_{i} \operatorname{covar}\left\{r_{i 1}{ }^{*} p_{i}^{*}\left(r_{i 1}+r_{i 2}\right)\right\}+\sum_{i \neq j} \sum_{j} \operatorname{covar}\left\{r_{i 1}{ }^{*} p_{i}^{*}\left(r_{j 1}+r_{j 2}\right)\right\} \\
\downarrow \\
\sum_{i} p_{i}^{*} \operatorname{var}\left(r_{i 1}\right)
\end{gathered}
$$

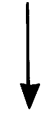

(because $\mathrm{r}_{\mathrm{i} 1} \& \mathrm{r}_{\mathrm{i} 2}$ from disjoint populations

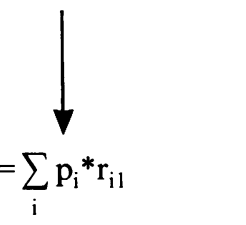

(because $r_{i 1}, r_{j 1}$ from disjoint age bands, $\&$ $\mathrm{r}_{\mathrm{i} 1}, \mathrm{r}_{\mathrm{i} 2}$ from disjoint populations too)

$$
=\sum_{\mathrm{i}} \mathrm{p}_{\mathrm{i}}{ }^{*} \mathrm{r}_{\mathrm{i} 1}
$$

(assuming $r_{\mathrm{i}}$ are Poisson)

Now let

$$
\begin{aligned}
& \sum_{\mathrm{i}} \mathrm{p}_{\mathrm{i}}^{*} \mathrm{r}_{\mathrm{i} 1}=\mathrm{q}^{*} \sum_{\mathrm{i}} \mathrm{r}_{\mathrm{i} 1}=\mathrm{q}^{*} \mathrm{D} \\
& \text { Then } \mathrm{q}=\sum_{\mathrm{i}} \mathrm{p}_{\mathrm{i}}^{*} \mathrm{r}_{\mathrm{i} 1} / \sum_{\mathrm{i}} \mathrm{r}_{\mathrm{i} 1}
\end{aligned}
$$

That is, an average of the $p_{i}$, weighted by the number of observed events in each age band. Hence Covar $(D, E)=q^{*} D$ where $q$ is given as above.

The method based on Fieller's approach is as follows:

$$
\mathrm{SMR}=\mathrm{D} / \mathrm{E}=\mathrm{R} \text { (say) }
$$

Then if D and E are "normal", so will $\left(\mathrm{D}-\mathrm{E}^{*} \mathrm{R}\right)$ be "normal" and

$$
\frac{\left(D-E^{*} R\right)^{2}}{\operatorname{Var}\left(D-E^{*} R\right)} \quad \begin{gathered}
\text { approximately as } \chi^{2} \text { on } \\
1 \text { degree of freedom }
\end{gathered}
$$

$$
\text { Now } \operatorname{Var}\left(D-E^{*} R\right)=\operatorname{Var}(D)-2 * R * \text { Covar }
$$$$
(\mathrm{D}, \mathrm{E})+\mathrm{R}^{2 *} \operatorname{Var}(\mathrm{E})=\mathrm{D}-2^{*} \mathrm{q}^{*} \mathrm{D} * \mathrm{R}+\mathrm{R}^{2 *} \mathrm{E}
$$

on using the above result for the covariance.

Confidence limits for $\mathbf{R}$ are solutions to the quadratic equation in $\mathrm{R}$ :

$$
\begin{array}{r}
\mathrm{R}^{2 *} \mathrm{E}^{*}\left(\mathrm{E}-\mathrm{X}^{2}\right)-\mathrm{R}^{*}\left(2^{*} \mathrm{D} * \mathrm{E}-\right. \\
\left.2 * \mathrm{D}^{*} \mathrm{q}^{*} \mathrm{X}^{2}\right)+\mathrm{D}^{*}\left(\mathrm{D}+\mathrm{X}^{2}\right)=0
\end{array}
$$

Where we use $\operatorname{var}(\mathbf{x})$ for a Poisson variate, and $\mathrm{X}^{2}$ is the critical value for $\chi^{2}$ appropriate for the desired confidence limits. 


\section{Appendix 2}

\# macro for $95 \%$ confidence limits on an SMR

$\#$

\#------------ data input---------------

noecho

erase $\mathrm{cl}-\mathrm{c52}$

\# housekeeping)

note Enter observed frequency

set 'terminal' c50;

nobs $=1$.

copy $\mathrm{c} 50 \mathrm{kl}$

note Enter expected frequency

set 'terminal' c50;

nobs $=1$.

copy c50 k21

note Enter average fraction of standard population

note that is the index $(=\mathrm{q})$

set 'terminal' c50;

nobs $=1$.

copy $\mathrm{c} 50 \mathrm{k} 22$

$\#$

$\#$

\# calculate $95 \%$ limits on observed no. using relation \# between Poisson and $\chi^{2}$ distribution

\#

let $\mathrm{k} 2=2 * \mathrm{k} 1$

let $\mathrm{k} 3=2 *(\mathrm{k} 1+1)$

\#

invcdf $0.025 \mathrm{k} 4$;

chisq $\mathrm{k} 2$.

let $\mathrm{k} 4=0.5 * \mathrm{k} 4 / \mathrm{k} 21$

$\#$

invcdf $0.975 \mathrm{k} 5$

chisq $\mathrm{k} 3$.

let $\mathrm{k} 5=0.5 * \mathrm{k} 5 / \mathrm{k} 21$

let $\mathrm{k} 6=\mathrm{k} 1 / \mathrm{k} 21$

$\#$

$\# \mathrm{k} 6=\mathrm{smr}$

\#

copy k5 c50

stack k4 c50 c50

stack k6 c50 c50

let $c 50=c 50$

\#

note

note *SMR and (L) and (U) $95 \%$ limits (if no error in expected)*

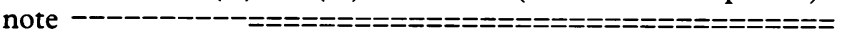
print $\mathrm{c50}$
\# Now find confidence limits for the proportion $\mathrm{O} /(\mathrm{O}+\mathrm{E})$ This \# treats $\mathrm{E}$ as if from a separate, control group. The confidence \# limits are conditioned on the sum $(\mathrm{O}+\mathrm{E})$ and uses the beta \# distribution, for which $\mathrm{E}$ does not need to be an integer

$\#$

let $\mathrm{k} 8=\mathrm{k} \mathbf{1}+\mathbf{1}$

let $\mathrm{k} 9=\mathrm{k} 21+1$

$\#$

invcdf $0.975 \mathrm{k} 10$;

beta $\mathrm{k} 8 \mathrm{k} 21$.

\#

invcdf $0.025 \mathrm{k} 11$;

beta $\mathrm{k} 1 \mathrm{k} 9$.

let $\mathrm{k} 10=\mathrm{k} 10 /(1-\mathrm{k} 10)$

let $\mathrm{k} 11=\mathrm{k} 11 /(1-\mathrm{k} 11)$

\#

copy $\mathrm{k} 10 \mathrm{c51}$

stack k11 c51 c51

stack k6 c51 c51

\#

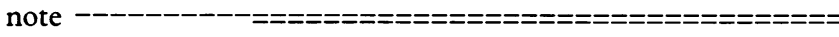

note $* * * * * *$ Values with error in expected (exact) $* * * * * * * *$

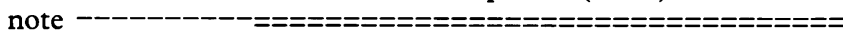

print $c 51$

\#

\# Now find approximate limits with Fieller's result

let $\mathrm{k} 13=\mathrm{k} 1 / \mathrm{k} 21$

let $\mathrm{k} 14=\mathrm{k} 21^{*}(\mathrm{k} 21-3.8416)$

let $\mathrm{k} 15=-2 * \mathrm{k} 1 *(\mathrm{k} 21-\mathrm{k} 22 * 3.8416)$

let $\mathrm{k} 16=\mathrm{k} 1 *(\mathrm{k} 1-3.8416)$

\#

let $\mathrm{k} 17=\operatorname{sqrt}(\mathrm{k} 15 * \mathrm{k} 15-4 * \mathrm{k} 14 * \mathrm{k} 16)$

let $\mathrm{k} 18=0.5^{*}(+\mathrm{k} 15-\mathrm{k} 17) / \mathrm{k} 14$

let $\mathrm{k} 19=0.5^{*}(-\mathrm{k} 15-\mathrm{k} 17) / \mathrm{k} 14$

\#

copy k18 c52

stack k19 c52 c52

stack k6 c52 c52

\#

note

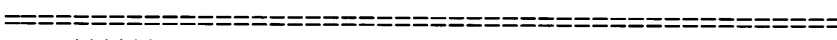
note $* * * * * *$ Values with error in expected (Fieller) $* * * * * * * *$ note

print $c 52$ 


\section{LETTERS TO THE EDITOR}

\section{Prevalence of total hip replacement: how much demand has been met?}

SIR - In their recent study, Williams et al ${ }^{1}$ found a substantial increase in the prevalence of total hip replacement compared with earlier years, and concluded that there was a greater level of satisfied demand. Before becoming complacent and basing policy decisions on this conclusion, however, cash-strapped purchasing authorities, struggling to meet the demand for total hip replacement in the UK, need to consider several other factors which are likely to increase demand still further.

Firstly, the study of Williams et al was confined to people $\geq 65$ years of age and one of the main contributory factors to the increased demand for total hip replacement is its application to younger patients. In our recent population based study of total hip replacement in Olmsted County, Minnesota (characterised inaccurately by Williams et al as an elective case series), people aged under 65 comprised $48 \%$ of all primary total hip procedures in men and $30 \%$ in women between 1987 and $1990 .^{2}$ Moreover, though the average age at surgery has remained relatively constant through the years, the range has increased. For example, the age range of women in 1969 was 62-82 (mean 69) years and in 1990 it was 29-91 (mean 70) years. This substantial use of total hip replacement in younger people is a strain on resources, a fact that is underemphasized by Williams et al. It also entails a substantial liability for revision surgery since the average life expectancy of these younger, more active people may exceed the expected useful life of the implants. ${ }^{3}$

Secondly, and following from above, the size of the elderly population is growing rapidly and their composition within the broad age groups that were studied (for example $\geq 75$ years) is changing: this has implications for provision for total hip replacement. Recent analysis of the data from $\mathbf{4 0 0}$ hospitals in the United States showed that while the number of people aged 85 years and over increased by $28 \%$, the proportion within that age group who received total hip replacement increased from 1.4 per thousand to 3.1 per thousand between 1980 and $1987 . .^{4}$ It would therefore be interesting to see a finer breakdown in ages and an assessment of the increased number of total hip replacement that might be needed in the future, even at current per capita surgery rates, solely because of the demographic changes in the UK.

Finally, with technological and medical advances, the indications for total hip replacement have increased. Primary degenerative joint disease in our study accounted for only $63 \%$ of the primary procedures, and not $76 \%$ as quoted by Williams et al. The other major category was hip fractures. Even though only a small proportion of hip fractures are treated with total hip replacement, these operations still accounted for nearly $20 \%$ of the total. ${ }^{2}$ With continued aging of the population, the number of people with hip fractures needing surgery will increase further. ${ }^{5}$ In addition, people with serious co-morbidities such as cancer and cardiovascular disease who may not have been considered good candidates for total hip replacement in the past are now being offered the procedure. ${ }^{4}$

The need for total hip replacement, or any other medical intervention, is a complex interplay of population demographics, patient and surgeons' attitudes, and economic and sociopolitical factors. We do not believe that the plateau for total hip replacement has been reached yet and support the call for further research into the needs... but for all age groups and for all indications.

$$
\begin{array}{r}
\text { RAJAN MADHOK } \\
\text { DAVID G LEWALLEN } \\
\text { LOSEPH MELTON, III } \\
\text { Orthopedic Surgery, } \\
\text { Departments of Health Sciences Researh and } \\
\text { Mayo Clinic and Foundation, } \\
\text { Rochester, MN 55905, USA }
\end{array}
$$

1 Williams MH, Newton JN, Frankel SJ, Braddon F, Barclay E, Gray JAM. Prevalence of total hip replacement: how much need has already been met? $\mathcal{F}$ Epidemiol Community Health 1994; 48:188-91.

2 Madhok R, Lewallen DG, Wallrichs SL, Ilstrup DM, Kurland RL, Melton LJ III. Trends in the utilization of primary total hip arthroplasty 1969 tization of prima a population-based study in Olmsted County, Minnesota. Mayo Clin Proc 1993;68:11-18.

3 Harris WH, Sledge CB. Total hip and total knee replacements. (First of two parts). $N$ Engl f replacements. (First of
Med 1990:323:725-31.

4 Friedman B, Elixhauser A. Increased use of an expensive, elective procedure: total hip replacements in the 1980s. Med Care 1993;31 581-99.

5 Hoffenberg R, James OFW, Brocklehurst JC, et al. Fractured neck of femur: prevention and management. $7 R$ Coll Phys Lond 1989;23:8-12.

\section{Aetiology of peptic ulcer in Norway}

SIR - Johnsen et $a l^{1}$ report an increased risk of duodenal ulcer in men with a high milk consumption. This factor was independent of age, cigarette smoking, and inheritance and the authors suggest that milk might increase duodenal ulcer risk by stimulating acid secretion through its calcium content.

In our analysis of the association between duodenal ulcer and calcium intake we found that the risk of duodenal ulceration increased with increasing intake of calcium in a doseresponse manner. ${ }^{2}$ In contrast to Johnsen's report this relationship was observed irrespective of sex. There was no correlation between calcium or milk intake and the duration of dyspeptic symptoms and none of the subjects reported a change in consumption of dairy products because of dyspepsia. These results make it less likely that increased milk consumption was a consequence of dyspepsia.

In summary, the findings of Johnsen's study and our own support a causal relationship between milk or calcium intake and duodenal ulcer risk.

B. BREUER-KATSCHINSKI, Zentrum für Innere Medizin Universitätsklinikum Essen, Hufelandsatr 55 4300 Essen 1, Germany
Department of Public Health Medicine and Epidemiology and Epidemiology, University Hospital, Queen's Medical Centre,
Nottingham NG7 2UH

1 Johnsen R, Førde OH, Straume B, Burhol PG. Aetiology of peptic ulcer: a prospective population study in Norway. $\mathcal{F}$ Epidemiol Community Health 1994;48:156-60.

2 Katschinski BD, Logan RFA, Edmond M, Langman MJS. Duodenal ulcer and calcium intake: a case-control study. Eur 7 Gastronterol Hepatol 1992;4:897-901.

\section{Corrigendum}

Estimating confidence limits on a standardised mortality ratio when the expected number is not

\begin{tabular}{|c|c|c|c|c|c|}
\hline & 0.2 & $0 \cdot 1^{q=}$ & 0.05 & 0 & Exact \\
\hline $\begin{array}{l}\text { Lower } 95 \% \\
\text { limit }\end{array}$ & 0.602 & 0.572 & 0.559 & 0.546 & $0 \cdot 546$ \\
\hline$\underset{\text { limit }}{\text { Upper } 95 \%}$ & $2 \cdot 840$ & 2.987 & 3.059 & $3 \cdot 131$ & 2.925 \\
\hline
\end{tabular}
error free. 1994;48:313-7.

The author wishes to correct some minor errors in the above article.

Firstly, in table 3 the numbers in the body of the table should be as follows:

Secondly, the quadratic equation which must be solved for $R$ in the appendix has a plus sign where there should be a minus sign, and should be:

$$
\begin{gathered}
\mathrm{R}^{2} . \mathrm{E} .\left(\mathrm{E}-\mathrm{X}^{2}\right)-\mathrm{R} \cdot\left(2 . \mathrm{D} \cdot \mathrm{E} \cdot-2 \cdot \mathrm{D} \cdot \mathrm{q} \cdot \mathrm{X}^{2}\right)+ \\
\text { D. }\left(\mathrm{D}-\mathrm{X}^{2}\right)=0
\end{gathered}
$$

Conference '95 - Canadian Society for Epidemiology and Biostatistics will be held on August 16-19, 1995 at St John's, Newfoundland. For information regarding registration and submission of abstracts, contact the conference office:

CSEB - Conference '95 Office, c/o Health Research Unit, PO Box 23068, St John's, Newfoundland, Canada A1B 4J6. Tel: 709 737-6720. Fax: 709 737-7382. 